\title{
Preening and Associated Comfort Behavior in Birds ${ }^{a}$
}

\author{
JUAN D. DELIUS \\ Experimentelle Tierpsychologie \\ Psychologisches Institut \\ Ruhr-Universität \\ D 4630 Bochum, Federal Republic of Germany
}

\section{INTRODUCTION}

The integument of birds has a considerably more complex structure than that of mammals. ${ }^{1}$ In most avian species the plumage also has an important extra function compared with the pelage of mammals: flight. Accordingly preening, as a behavior that conditions the bird's integument, can be expected to play a more important role within the activity repertoire of birds than grooming does in that of mammals. Indeed preening is generally a very elaborate behavior that takes up a considerable proportion of the time budget of birds. For example, van Rhijn ${ }^{2}$ has impressively documented the complexity of the preening behavior of gulls, and I have found that during the breeding season and at daytime $15 \%$ of their time was taken up by this activity. ${ }^{3}$ During moonlit nights (unpublished observations) the preening took up almost as much of the gulls' time $(12 \%)$. Pigeons interrupt sleeping in complete darkness virtually only to preen ${ }^{4}$; gulls can be expected to do likewise.

Although preening is such a frequent behavior among birds, our knowledge about it is still sparse and disconnected. To give this brief review the wisp of a plot, it takes the form of a somewhat personal narrative. Besides preening proper (drawing feathers through the beak), a number of other comfort patterns that are more or less closely related to preening, either motivationally or functionally, will be mentioned. The reader should realize that there are several other behaviors of this kind that, though obviously important to birds, I will not refer to. As a striking, rather exotic example, one can mention anting, or bathing in a heap of ants, an activity many bird species seem to love!

\section{OCCURRENCE AND STRUCTURE OF PREENING}

Compared with many other behavioral responses, the timing of preening is usually not critically dependent on specific environmental events. By and large, as a preventive body-surface maintenance activity, it does not have to be done at any particular time as long as it is done sometime and at intervals that are not too far apart. It would

${ }^{a}$ Most of the research done in our laboratory was supported by the Deutsche Forschungsgemeinschaft through its Sonderforschungsbereich 114. Pierre Deviche (now at the Dept. of Zoology, Oregon State University, Corvallis), who contributed much to the research reported, held Humboldt and NATO fellowships while in Bochum. 
seem to be a kind of spare-time activity that is performed whenever there is nothing more important to do. Gulls in the wild, subject as they are to all kinds of selective pressures, spend less time preening than well-provided-for, aviary caged gulls (15\% versus $26 \%$ of their time, $p<0.01$; own observations). In contexts that make little demand on the animals, and in an undisturbed environment, rhythmicities with periods on the order of several tens of minutes may be predominant in determining the occurrence of preening. ${ }^{5}$ Over and above these short cycles, a diurnal cycle is often very apparent ${ }^{6}$ (but compare ref. 3 ). It is not certain whether it is directly due to a central circadian rhythm, or secondary to the dark-light cycle. It is well documented that periodic external stimuli such as light pulses can entrain the short-term cyclic occurrence of preening. ${ }^{\text {? }}$

Some preening-related behavior can, however, become strongly stimulus dependent in particular situations. I have observed skylarks to respond forthwith with sunbathing behavior during prolonged cloudy-foggy weather spells whenever the sun managed to break through and to immediately begin with rainbathing behavior during extended hot-dry weather spells whenever it began to drizzle. ${ }^{6}$ Deprivation of the opportunity to dustbathe leads to a cumulating increase in the probability that chickens will show this behavior as soon as dust is made available. ${ }^{8}$ There are also, undoubtedly, events that require immediate preening attention by birds. This might be the case with the more offensive activities of integument parasites, ${ }^{9}$ disturbances due to feather loss and growth (molting seems to intensify preening in pigeons), and disturbances due to wind gusts or the behavioral activities of the bird itself or those of other birds. Particularly short duration bouts of preening are thought to be primarily elicited by such acute cutaneous, and sometimes visual, stimuli. ${ }^{\text {to }}$

This evidence indicates that local somesthetic stimuli may, on the one hand, trigger and direct preening. On the other hand, they are probably not essential for preening to occur and to be structured. Lefebvre and Joly ${ }^{11}$ (see also ref. 5), for example, argue on the basis of a detailed analysis of extensive observational data that the longer preening bouts of kestrels are not initiated by any particular stimulus. They also conclude that

TABLE 1. Local and Overall Preening of Dorsally Denervated and Sham-Operated Control Pigeons Unstimulated and Stimulated with Itching Powder Applications to the Dorsal Skin

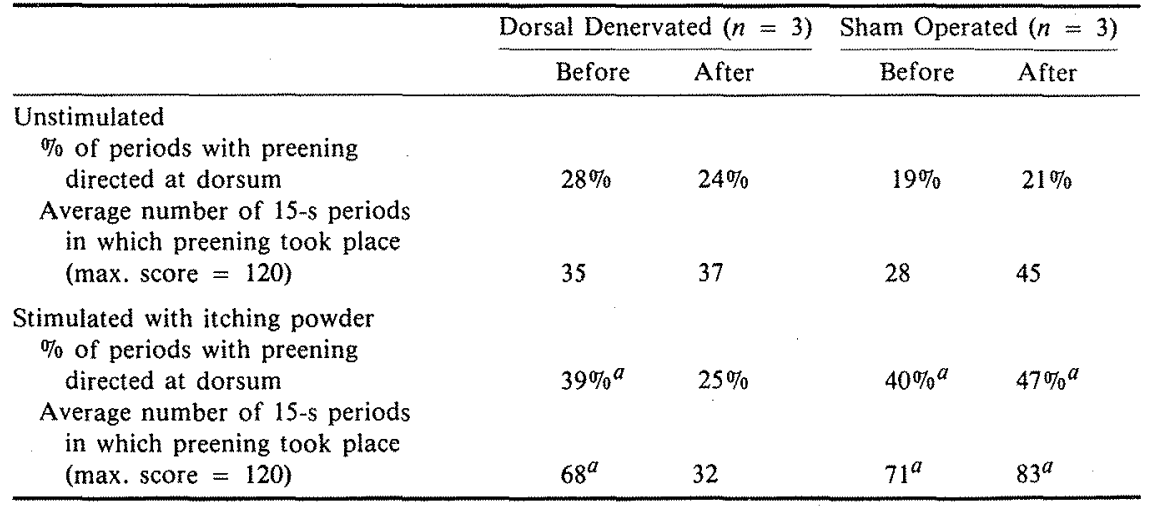

Based on 3 preoperative and 3 postoperative 30 -min sessions on 6 birds. All figures are rounded to the nearest whole number.

${ }^{a}$ Significantly different from equivalent (unsuperscripted) averages $(p<0.05$ or less). 


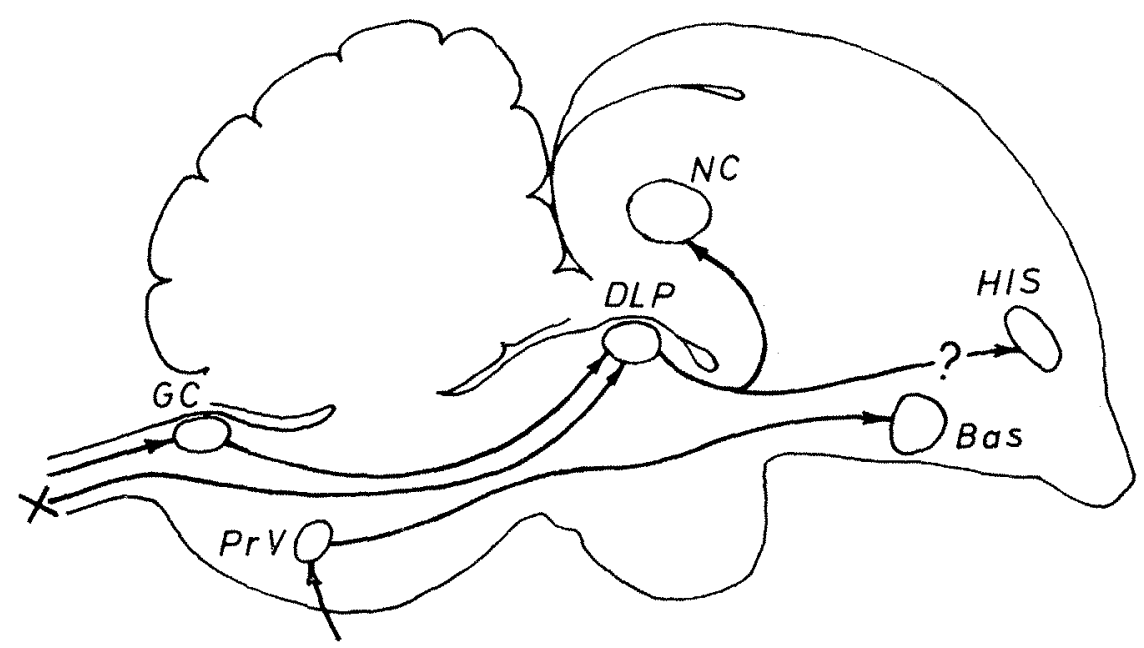

FIGURE 1. Scheme of the somatosensory projections to the forebrain of the pigeon: $D L P$, nucleus dorsolateralis posterior; $G C$, nucleus gracilis et cuneatus; $N C$, neostriatum caudale; $H I S$, hyperstriatum intercalatus superior; $\operatorname{Pr} V$, nucleus sensorius principalis nervi trigemini; Bas, nucleus basalis prosencephali (updated from Delius and Bennetto ${ }^{15}$ ).

the organization of these bouts, in terms of the body areas sequentially preened, is determined by a hierarchical, stochastic control system (a noisy "grammar") that is largely independent of specific external stimuli.

Our own unpublished experimental data (partly obtained in collaboration with $\mathrm{K}$. Benetto) on pigeons that had a large patch of the dorsal skin surgically denervated by removing a small length of six to eight pairs of dorsal cutaneous nerves and control animals that were sham operated support this view. The pigeons continued to preen spontaneously the dorsum as much, but not significantly more, than they had done before surgery, not differing in this from the controls. Itching powder (cowhage) applied to the dorsal skin of the sham-operated pigeons markedly augmented the proportion of preening movements directed at this region but also increased somewhat the preening directed at other body areas. The dorsally denervated pigeons did not show a special response to the dorsal application of itching powder, preening this region about as much as they did normally, when not specially stimulated, confirming that they had been effectively denervated (TABLE 1). Thus local stimulation is not essential to organize the normal sequence of preening movements, although it can certainly initiate and direct preening. The evidence suggests that bird preening might not be much different from mammalian grooming in this respect. ${ }^{12}$ Incidentally, in view of the context the comparisons with mammals will be kept to a minimum; readers are referred to the relevant contributions in this volume.

Contrary to former opinions, the furnishing of the avian skin with sensory receptors is at least comparable to that of mammals. ${ }^{13}$ Some arrangements are quite specialized for detecting plumage derangement. ${ }^{14}$ There is thus a substrate that can mediate preening triggered by cutaneous stimuli. An effort was made to localize the somesthetic projection areas in the avian brain in the hope that they may somehow be involved in this control. Using the evoked potential technique, three such areas were located in the 
forebrain of pigeons, two in the telencephalon, and one in the thalamus. A further, purely trigeminal, telencephalic projection area was already known ${ }^{13.15}$ (FIG. 1). Exploratory experiments involving lesions of the two telencephalic areas (the thalamic and trigeminal projections were not investigated), however, did not reveal any modification of preening. Neither did explicit electrical stimulation of these areas through implanted electrodes elicit any excess preening (see also below). It thus would seem that the somesthetic sensory system links up with the preening motor system at a lower level of the neuraxis than the telencephalon (but see below).

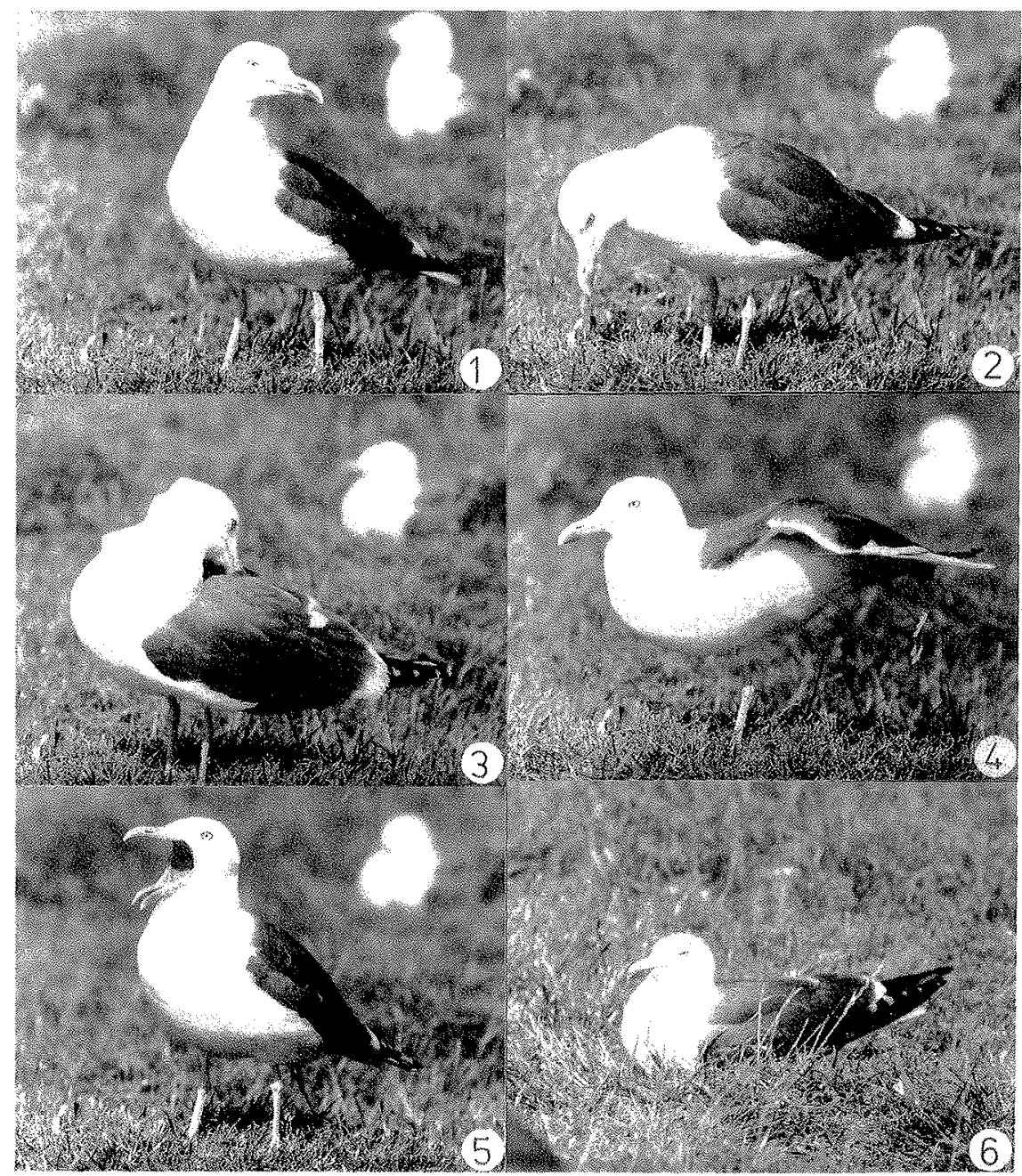

FIGURE 2. Response of a gull to a slight, brief disturbance. After an alarm response (neck stretch, $l$ ) it stares down (2), preens (3), stretches one wing and leg (4), yawns (5), and after moving away a few steps squats down and becomes drowsy (6). Between these responses it repeatedly eyed the source of disturbance. 


\section{DISPLACEMENT PREENING}

In addition to normally occurring preening, some other comfort patterns make occasional appearances in contexts that are anything but relaxed. This has been described by ethologists as displacement behavior. ${ }^{16.17}$ In situations that can be calculated to be somewhat stressful (involving motivational conflict), birds (and indeed also other animals including humans) often show brief bouts of comfort behavior, and some other equally irrelevant responses, embedded among behaviors more directly related to resolving the situation inducing the stress. FIGURE 2 shows a sequence of behavior that demonstrates the point. The photographer waggled a finger out of a slit of a hide placed in the middle of a gull breeding colony when the animals were at ease. Birds nearby immediately responded with an attentive neck elongation, wide-open eyes, and a few alarm calls; some actually flew away. Then the finger was withdrawn again and before relaxing most of the remaining birds showed a peculiar sequence of responses including a brief bout of preening. The bird photographed finally moved a few steps away and squatted down, soon showing signs of drowsiness (see also ref, 18). On a more global scale, a similar but more intensive delayed preening response to a stressing event was observed when surrounding birds were alarmed by brief and energetic arm waving from a tower emplaced in the middle of the gull colony. A high level of behavioral arousal was so induced. The gradual return to normal that followed was marked by a burst of preening and indeed other comfort responses not recorded in detail ${ }^{3}$ (FrG. 3).

Experiments involving electrical brain stimulation through chronically implanted electrodes in awake, unrestrained (but captive) gulls showed that certain brain loci pro-
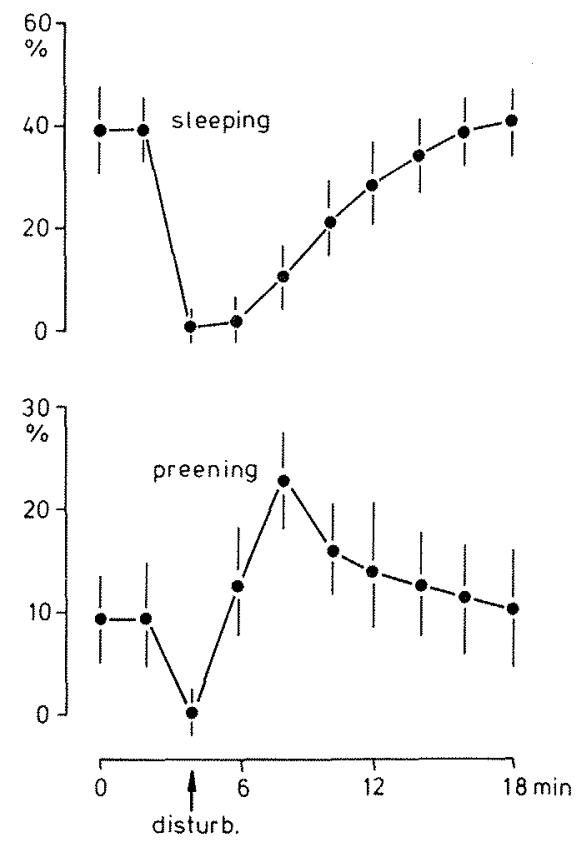

FIGURE 3. Time course of preening and sleeping responses of gulls following a brief, strong disturbance. Means ( \pm SD) based on 10 sessions, sampling of $>100$ individuals (after Delius ${ }^{3}$ ). 
duced a behavior syndrome bearing a close similarity to the response pattern described above. ${ }^{19}$ Upon brief stimulation of such a locus, two or more of the following behavioral responses were elicited: staring down, pecking, preening, relaxation, yawning, squatting, drowsiness, and sleeping (compare with Fig. 1; pecking sometimes follows staring down, and sleeping frequently ensues after drowsiness). These responses were shown upon stimulation, most often in the sequence listed with latencies that varied between a few seconds to a few minutes (FIG. 4a). The anatomical location of the stimulation sites that yielded this preening cum relaxation syndrome are illustrated in Frgure $4 \mathrm{~b}$. Most of them appear to cluster along the lateral wall of the anterior section of the forebrain ventricle, including the nucleus accumbens, the medial neostriatum intermedium, the lateral neostriatum intermedium, the posterior hippocampal complex, and perhaps the posterior ventral hypothalamus. It may be worthwhile to point out also the two loci near the nucleus basalis, since this structure will be mentioned again later on.

A key fact was that the activation of these brain sites tended to elicit drowsiness and sometimes even sleep, besides the other responses. This can be related to the frequent mention of sleep behavior, along with comfort and a few other behaviors, in the displacement activity literature. ${ }^{20}$ Together with some other evidence these findings led to the formulation of a dearousal hypothesis of displacement activities. It was meant to compete with a then-current disinhibition theory of the same phenomenon. According to this latter theory there is a mutual inhibition between motives activated by the stress situation that leads to the disinhibition of a background motive yielding irrelevant displacement responses. 18.21 $^{2}$

Stressful situations of the kind that elicit displacement activities were thought, according to the dearousal hypothesis, to involve an excessive information processing activity in the brain (having to do with the operation of deciding whether and what corrective behavioral action is to be taken in response to the stressing situation). This was conceived as leading to a greater activation of neural networks than could be coped with effectively. Such an information overload, or overarousal, would trigger corrective action such that mechanisms designed to dampen the information processing rate

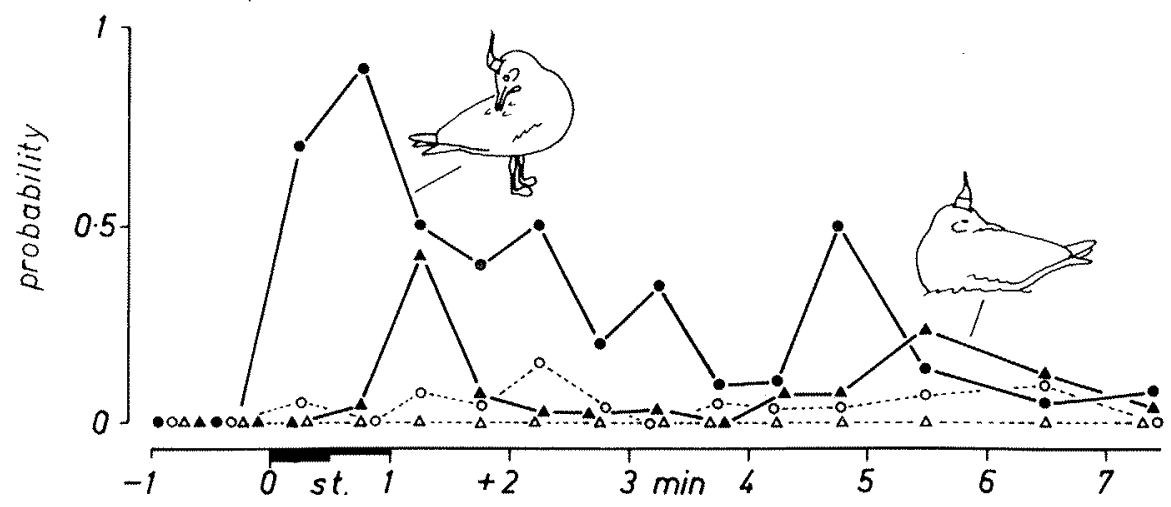

FIGURE 4a. Brain-stimulation-elicited preening and dearousal in gulls. Time course of probability of occurrence of preening and sleeping per 30 -s periods. Averages for two lateral neostriatum intermedium sites, 12 trials each, $50-\mu \mathrm{A}$ stimulation trains lasted 30 or $60 \mathrm{~s}(\mathrm{st}$.). Open symbols and dashed lines are results of control dummy trials. 


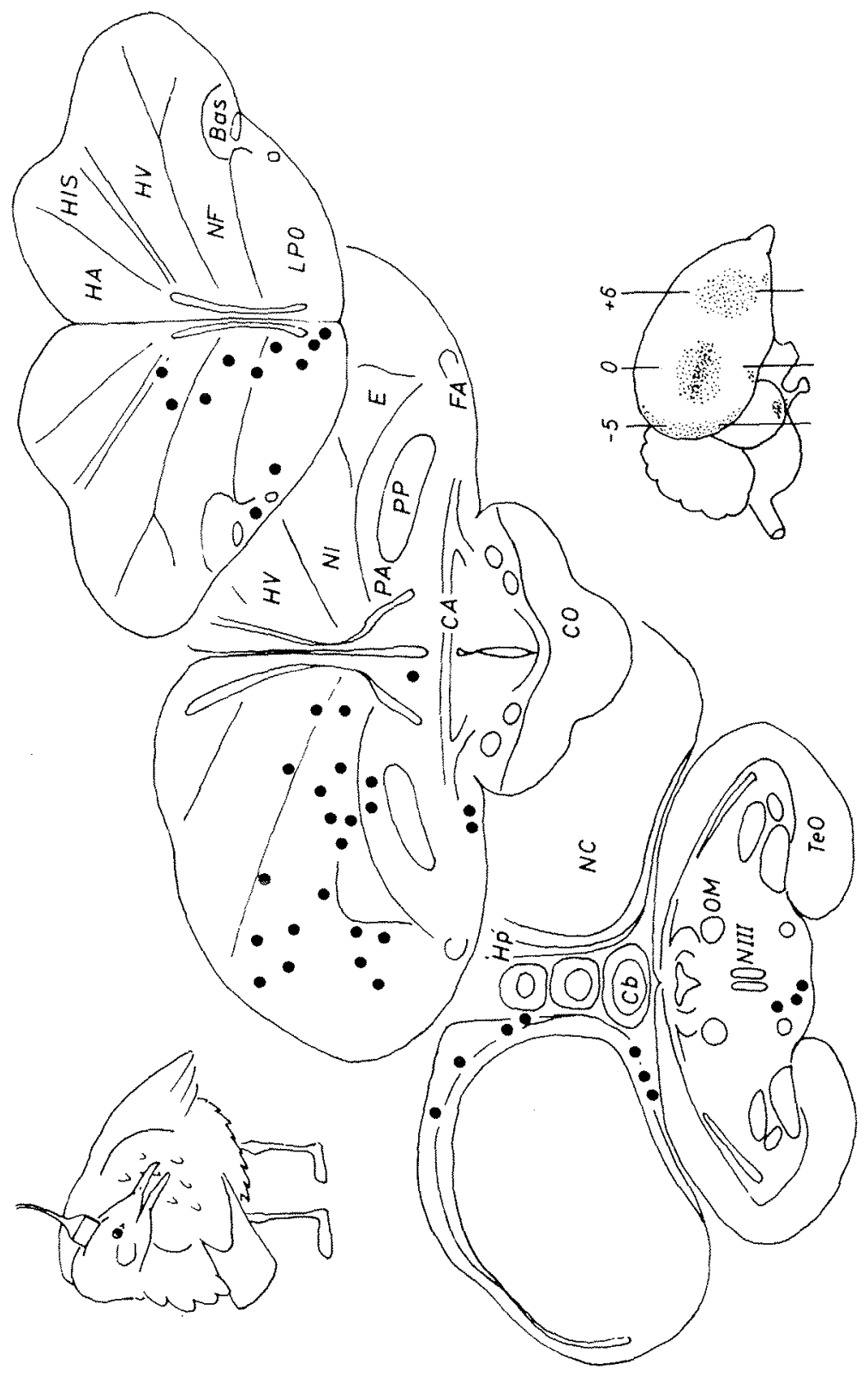

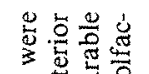

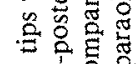
동용 농용 政要 5 런 웡워 욤 $\stackrel{s}{3}$

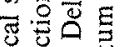
E.

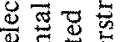
동영 on

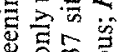
吅骂 호을 氜造 $\Rightarrow \infty$

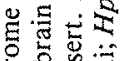
它总要 के

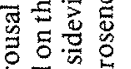
욜

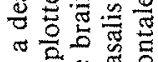

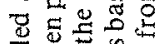

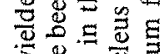
글

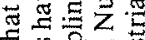

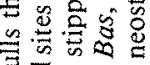

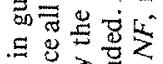

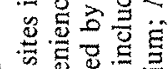

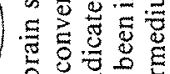
定造. 政

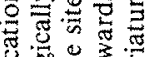

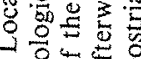
总完要 월

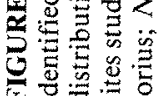


for the purposes of neural rest or regeneration (drowsiness, sleep) would act to bring the activation back into the range where efficient (adaptive) information processing was again possible. The concept is one of neural arousal homeostasis ${ }^{20}$ (see also ref. 22). Preening and other behavior that is neurally coupled to sleep (see results of the stimulation experiments mentioned above) would be incidentally coactivated or perhaps even contribute to the dearousing process. Weak, repetitive cutaneous stimulation as might arise during preening, for example, has been said to act in such a manner.

Some efforts were made to support the arousal homeostasis hypothesis with further kinds of evidence, now using pigeons. The essential element of the hypothesis is the assumption that there is an arousal-regulating negative feedback loop in operation. The most direct analytical approach suggested by elementary systems theory considerations is to attempt to cut open the loop. Based on some of the brain stimulation results (Fig. 4b), it was surmised that the hippocampal formation could be the critical link of such a circuit. In a first experiment pigeons with bilateral hippocampal lesions, when exposed to a mildly stressing situation, a novel cage, showed a significantly lesser preening and a significantly greater behavioral arousal increment than control shamoperated pigeons, even though the preening activity of the hippocampal birds in their home cage environment did not differ from that of the controls. The result accorded nicely with the hypothesis, but in later experiments they could not be replicated. These experiments rather revealed a considerable inter- and intraindividual variation of the preening evoked by the stressing stimulus. The handling associated with the procedure was probably stressing in itself and also caused plumage disturbances that directly induced preening (see above), masking any differences that may nevertheless have been due to the different surgical treatments. If hippocampal lesions have an effect on stressinduced preening, it is more subtle than our methods could reveal. In any case even the demonstration of a weak effect would be insufficient to support the specific hippocampus-mediated version of the dearousal hypothesis. The negative results do not, however, disprove the more general idea, as structures other than the hippocampus may mediate the dearousal feedback postulated.

More generally, we have found it difficult to devise a laboratory test that reliably yields a quantifiable displacement response in pigeons, even though casual observations of feral pigeons leave little doubt about the existence of the phenomenon, including preening and other comfort behaviors, in this species. It may be that operant conditioning techniques could provide a solution. ${ }^{23}$

A regularly occurring, brief, preening-like behavior of pigeons has been labeled "displacement preening." ${ }^{24}$ It is often incomplete in that the animal's bill does not touch the scapular feathers at which it is directed. ${ }^{25}$ In the opinion of a pigeon sexual behavior expert (M. Abs, personal communication), the movement is part and parcel of their courtship ceremony, that is, a highly ritualized display ${ }^{17}$ that no longer has the character of a proper displacement activity.

Another approach attempted to substantiate further the assumption that preening is truly associated with neural dearousal. As an index we employed the electroencephalogram (EEG) recorded from chronic depth electrodes variously placed in the forebrain of freely moving pigeons. Birds show EEG changes, from the desynchronized pattern to the synchronized pattern, as they proceed from a very awake state to an asleep state, much as do mammals ${ }^{26}$ (so-called rapid eye movement, desynchronized EEG sleep is rare in birds). Preening was indeed found to be accompanied by slow wave, highamplitude activity. With the technique employed, however, it was possible that subtle cable-movement artifacts were interfering with the recording. Pecking, also involving rapid head movements, for example, also correlated with the appearance of slow waves in the EEG. Still, that would in itself not necessarily be incompatible with the dearousal hypothesis, as pecking also occurs as a displacement activity in birds. More recent 
pigeon EEG recordings, however, made during experiments with a different intention but with a technique that excludes cable artifacts, confirm the original observations that slow waves are often associated with preening and pecking. The objection now is that these newer recordings may suffer from another kind of movement artifact, namely those due to a mechanical displacement of brain tissue itself. This issue is as yet unresolved.

\section{CORTICOTROPIN PREENING?}

It is well known that stress activates the adrenocortical system. Could stress-induced behavior be an effect due to the corresponding hormonal processes? Inspired by the report of Gessa et al. ${ }^{27}$ that intracerebroventricular (i.c.v.) administration of adrenocorticotropic hormone (ACTH) elicited yawning and stretching behavior in cats and other mammals and the fact that these responses have been reported as displacement activities in the relevant species, we examined the effect of the same treatment in birds. The result was that doses of 1 or more international units (IU) of ACTH injected into the lateral forebrain ventricles of pigeons through chronically implanted cannulae yielded yawning and headshaking with short latencies ${ }^{28}$ (FIG. 5). Even though we specifically looked for an effect on preening we could not demonstrate a quantifiable one. A more detailed study ${ }^{29}$ confirmed but also extended the above results. The frequency of wingflapping and a behavioral arousal index increased, and the frequency of eye closing and of single wing-stretches decreased with i.c.v. ACTH. Preening was again unaffected by the hormone administration, even though the dosage was varied. No short-term changes of behavior could be observed in pigeons when ACTH was administered intravenously. Initially this was seen as indicating that the i.c.v. effect was purely a pharmacological, rather than a physiological effect. It is now clear, however, that ACTH and other peptides related to it function also as ventricular liquormones and as synaptic modulators.

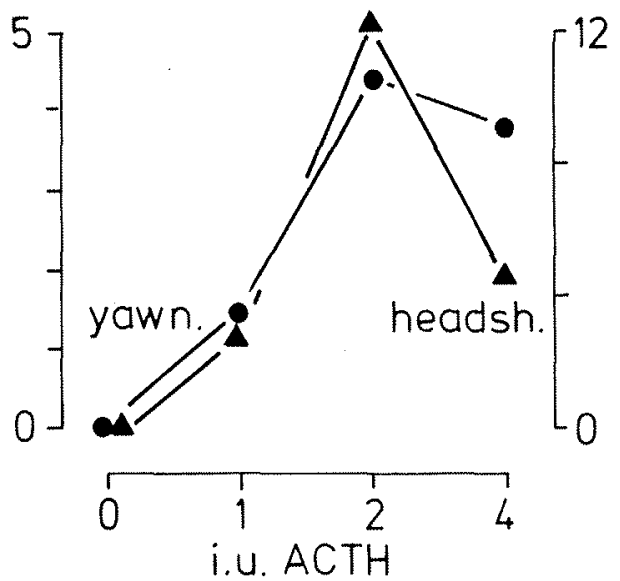

FIGURE 5. Yawning and headshaking elicited by i.c.v. administration of ACTH in pigeons. Abcissae: Mean number of responses shown during $50 \mathrm{~min}$ after the injections. Each datum is a mean of nine trials with four pigeons. (From Delius et al. ${ }^{28}$ ). 

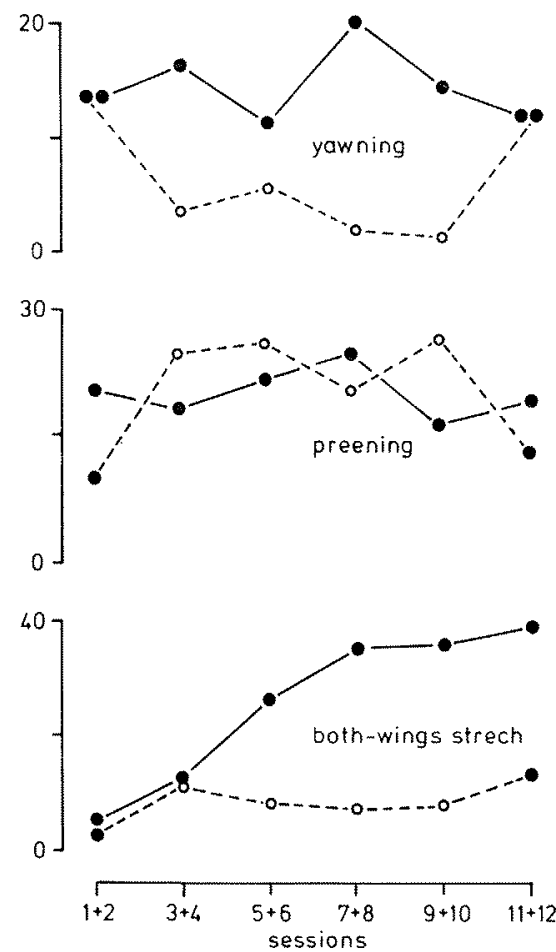

FIGURE 6. Is there sensitization or tolerance with i.c.v. ACTH-induced behavior in pigeons? Before sessions 1, 2, 11, and 12, all pigeons received 2 IU ACTH (•). Before remaining sessions experimental pigeons (solid lines, $n=4$ ) also received ACTH but control pigeons (dashed lines, $n=3$ ) received saline injections $(O)$. Abcissae: number of 60 -s periods in which the relevant behavior occurred (max.60). Comparison between mean scores of sessions 1 and 2 and scores of sessions 11 and 12 reveals a significant sensitization effect for both-wings stretch $(p<0.05)$, but no effects for yawning and preening (see also text; after Neveling ${ }^{32}$ ).

It was then suspected that some of the behavioral responses to ACTH might be affected by sensitization or tolerance effects induced by repeated injections. Such effects are known to occur with many behaviorally active drugs (see for example refs. 30 and 31). A study directed by Pierre Deviche in our laboratory was designed to detect these effects. ${ }^{32}$ For preening, as well as other comfort patterns, including yawning, headshaking and wingflapping (see above), neither a sensitization nor a tolerance effect was found. In the case of the both-wing-stretch pattern, however, there was sensitization (FIG. 6). This behavior can thus also be elicited by i.c.v. ACTH, but only after a preceding course of several daily hormone injections.

Another study ${ }^{45}$ supervised by Deviche investigated whether the ACTH syndrome was perhaps due to the activation of opiate receptors. ACTH administered by the i.c.v. route $(20 \mu \mathrm{g} / 4 \mu \mathrm{l})$ elicited significantly increased yawning, headshaking, bodyshaking, wingflapping, and decreased preening. Bodyshaking had not been described to be part of the i.c.v. ACTH syndrome before. Naloxone, an opiate antagonist given either i.c.v. $(20 \mu \mathrm{g} / 4 \mu \mathrm{l})$ or i.m. $(2 \mathrm{mg} / 0.5 \mathrm{ml}) 10 \mathrm{~min}$ before the ACTH did not modify the re- 
sponse to the hormone, except perhaps in the case of preening where the inhibition caused by ACTH appeared to be slightly reduced. Naloxone given by itself did not have any effect on the occurrence of any of the behaviors mentioned. Furthermore, i.c.v. injections of up to $5 \mu \mathrm{g} \beta$-endorphin and up to $10 \mu \mathrm{g}$ Met-enkephalin had no effect on the comfort behavior of the pigeons.

In a further study under Deviche's direction, von Uslar ${ }^{33}$ found that $\mathrm{ACTH}_{1-39}$ and $\mathrm{ACTH}_{1-24}$ is superior to [D-Phe-7]ACTH ${ }_{4-10}$ in eliciting comfort response in pigeons. The two long chain peptides were also found to augment the occurrence of mandibulation (small jaw and tongue movements), a behavior that had not been scored previously. Preening, on the other hand, was depressed by them. Only in releasing head and body shaking was [D-Phe-7] $\mathrm{ACTH}_{4-10}$ just as effective as the longer peptides. Simple $\mathrm{ACTH}_{4-10}$ was found to be completely ineffective. All peptides were given at a dose of $20 \mu \mathrm{g}$ per pigeon. Incidentally, this dose (as well as those mentioned previously) are some 10 times higher than those needed in mammals (pigeons weigh about 500 g). We have no explanation except that birds generally seem to require higher dosages of pharmacological agents. Their higher metabolic turnover rate may have something to do with it.

In spite of the fact that in the studies mentioned there was no increase, and sometimes even a decrease, in preening (but see ref. 34 for different results in chickens), the impression persisted that this behavior was somehow affected in an interesting way by i.c.v. ACTH even though this was not reflected in the data recorded. Data to support this impression was finally obtained by von Uslar. ${ }^{33}$ Her scoring scheme for preening was more detailed than that used in our previous studies. She recorded as separate categories nonpreening and the preening of eight different body regions (breast, belly, shoulder, wing outside, flank-wing inside, back, tail, and head rubbing or scratching) with a time resolution of 0.5 seconds. Based on observations of six ventricle cannulated pigeons and using a balanced intrasubject treatment design, she established that within a period of $45 \mathrm{~min}$ after an ACTH injection $(20 \mu \mathrm{g})$ the pigeons preened on average only for $27.8 \mathrm{~s}$, whereas after control saline injections the same pigeons preened on average for $194.5(p<0.01)$. The difference would not have emerged as significant had our usual simpler system of check-scoring been employed.

Defining a bout as a sequence of preening acts interrupted by not more than 30 $s$ of nonpreening (a criterion that we had found useful in previous studies; see also ref. 5), she also showed that the number of preening bouts produced by the pigeons while ACTH injected did not differ from that shown while treated with saline (6.1 and 6.5 bouts respectively, $p>>0.05$ ). Consequently, however, the durations of the

TABLE 2. Composition of Preening of Pigeons after i.c.v. Injections of ACTH and Saline ${ }^{a}$

\begin{tabular}{lrr}
\hline & ACTH & Saline \\
\hline Belly & 6.5 & 9.8 \\
Breast & 12.2 & 7.2 \\
Shoulder & 13.7 & 8.4 \\
Wing (outside) & 29.9 & 27.2 \\
Wing (inside) & 5.6 & 13.0 \\
Back & 20.3 & 25.2 \\
Tail & 7.7 & 6.0 \\
Head & 3.5 & 2.6 \\
\hline
\end{tabular}

${ }^{a}$ Composition of preening is indicated as percentages of total preening time directed at body areas, based on averages derived from 45 -min sessions after injections, 2 sessions per condition, $n=6$ pigeons (from von Uslar ${ }^{33}$ ). 
bouts during the ACTH treatment were considerably briefer than under the control situation ( 4.6 and $29.9 \mathrm{~s}, p<0.01$ ). She also demonstrated that under ACTH and saline the composition of preening in terms of the different body areas preened does not differ. Indeed the relative times spent on preening the various areas is equivalent (TABLE 2, $p>>0.05$ ). What happens is that when treated with ACTH, the animals preen each of the body regions for less time than when treated with saline (on average $1.6 \mathrm{~s}$ versus $4.6 \mathrm{~s}$ per region, $p<0.05$ ). This agrees well with the difference between normal and displacement preening reported by Duncan and Wood-Gush ${ }^{35}$ for chickens. Based on cinematographic recordings, these authors established that displacement preening was more hurried than normal preening, in agreement with frequent but unsupported statements in the displacement behavior literature.

Still, stress also induces an increase in preening (see Fig. 3). Thus the ACTH syndrome in pigeons does not succeed fully in matching their displacement behavior. There is also a striking disparity with mammals where the stress hormone does activate the equivalent of preening, grooming, in addition to yawning and stretching. ${ }^{36,31}$

\section{DOPAMINERGIC PREENING}

Recent pharmacological experiments on pecking in pigeons (a theme not unrelated to displacement activities, as commented earlier) have yielded some results that are

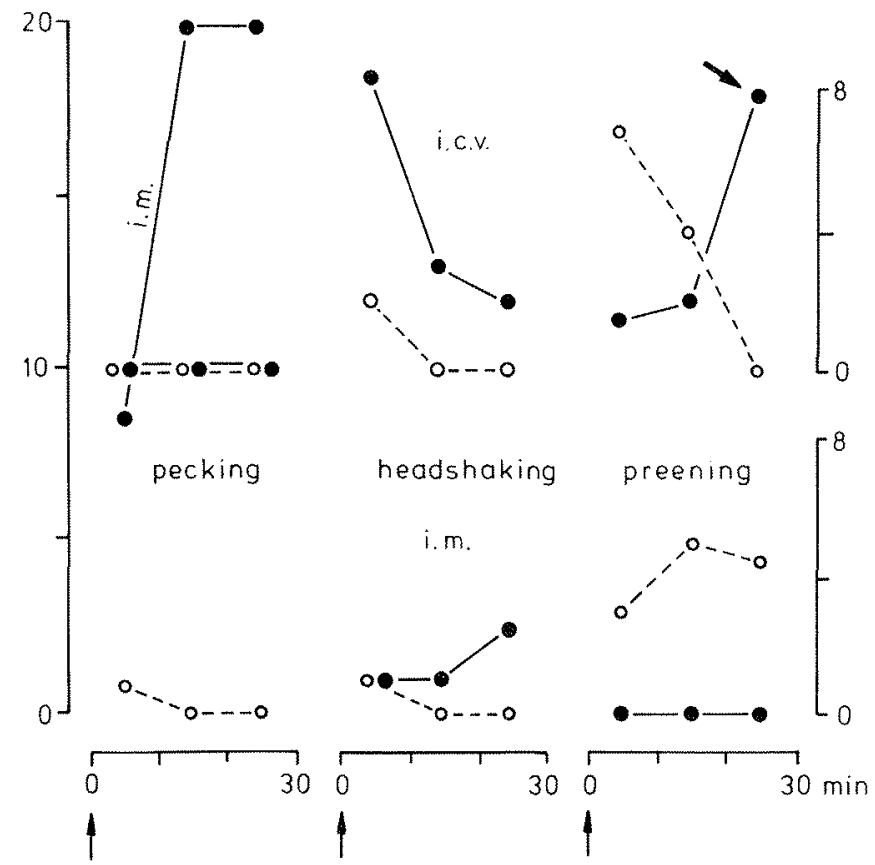

FIGURE 7. Response elicited in pigeons by apomorphine (๑) and saline (O). Below, i.m. (1.5 $\mathrm{mg}$ ) injections; above, i.c.v. $(60 \mu \mathrm{g})$ injections. Abcissae, number of 30 -s periods per $10 \mathrm{~min}$ with the relevant behavior (max. 20); arrows indicate injections. For pecking the scale of the i.m. apomorphine response extends into the top of the figure. Note delayed, significant $(p<$ 0.01 ) increase of preening after i.c.v. injections (modified from Deviche ${ }^{39}$ ). 
relevant in the present context. It is well known that apomorphine, a potent dopamine (DA) agonist, elicits persistent fits of pecking in pigeons when injected intramuscularly (i.m.) at doses above $0.75 \mathrm{mg}$ per pigeon. ${ }^{37.30}$ The occurrence of preening is at the same time strongly inhibited. Lower doses of i.m. apomorphine $(0.05 \mathrm{mg})$, however, may facilitate preening. ${ }^{38}$ Apomorphine given i.c.v. $(60 \mu \mathrm{g})$ does not, remarkably, elicit any pecking at all but with some delay significantly enhances preening (Frg. 7) Headshaking, incidentally, is elicited by both i.m. and i.c.v. apomorphine injections. ${ }^{39}$ This suggests that similarly to pecking, preening can be driven by dopaminoceptive neural elements although it is easily overshadowed by more potently elicited responses.

In an attempt to identify the central nervous structure where apomorphine actually elicits pecking, Lindenblatt ${ }^{40}$ injected intracerebrally (i.c.) microquantities $(20 \mu \mathrm{g}$ in $1 \mu$ l solvent) of its L-isomer into various brain structures. She employed cannulae that were acutely inserted through previously stereotactically implanted guide tubes. The control treatment consisted of injections of the inactive $\mathrm{D}$-apomorphine isomer.

Although other brain structures may also be relevant, preliminary results already imply that the main effort so far is concentrated on the avian nucleus basalis area in the frontolateral telencephalon (see Fig. 1 and Fig. $4 \mathrm{~b}$ for its general location). It is now certain that apomorphine stereospecifically induces pecking at this site. ${ }^{41} \mathrm{Re}$ markably, however, preening is also activated by the I-apomorphine injection at most of the basalis sites. Of nine histologically verified basalis injection sites, $7(77 \%)$ yielded more preening with $\mathrm{L}$ - than with $\mathrm{D}$-apomorphine injections, whereas in the surrounding brain tissue, of 18 sites only 6 yielded more preening $(30 \%)$ with L-apomorphine. FIGURE 8 gives an example of the time course of the effect and also locates the relevant positive injection sites as well as some of the negative sites.

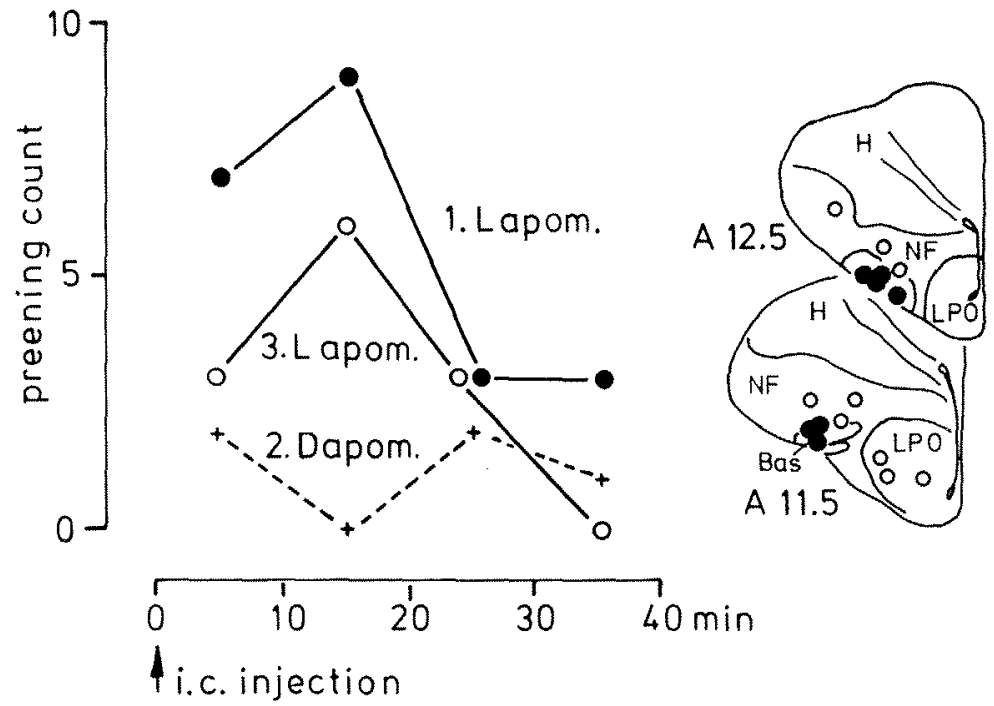

FIGURE 8. Left, Preening after intracerebral injections of $\mathrm{L}$-apomorphine (first and third injection) and $\mathrm{D}$-apomorphine (second injection) into the nucleus basalis of the pigeon. Abcissa, Number of 30-s periods with preening. Right, Sites where L-apomorphine elicited more preening than D-apomorphine ( $)$ and some of the sites where no such effect was found $(O)$. Data from Lindenblatt ${ }^{40}$ and personal communication). 
This evidence of an involvement of dopaminergic mechanisms in avian preening is interesting because a similar situation seems to apply to grooming in mammals even though the particulars seem to be in dispute. ${ }^{31,42}$ At this point it is premature to speculate about the possible links between stress, ACTH, and DA in birds because of lack of data. That the nucleus basalis may be concerned with the control of preening is very remarkable. Until now this exclusively avian structure was thought to be a substrate dedicated to the sensorimotor coordination of feeding, or more precisely concerned with the pecking and grasping of food. ${ }^{30}$ The various sensory afferences (auditory, vestibular, olfactory) it receives besides the somesthetic illustrated in FIGURE 1 certainly qualify it for that role. ${ }^{43.44}$ On the other hand they may make it just as well suited to control the subtle head and bill movements that constitute preening. Grasping grains or feathers are after all not very different operations. A link of this kind between pecking and preening may help to explain the peculiar association of these patterns in displacement contexts. However that may be, the dopamine connection promises to be a profitable research avenue to the central mechanisms of avian preening.

\section{ACKNOWLEDGMENTS}

I thank Dagmar Hagenkötter for patient help in preparing, and Julia Delius for editing, this manuscript. G. Keim assisted with the artwork.

\section{REFERENCES}

1. Lucas, A. M. \& P. R. Stetrenhem. 1972. Avian Anatomy, Integument. U.S. Department of Agriculture. U.S. Government Printing Office. Washington, D.C.

2. VAN RHIN, J. G. 1977. The patterning of preening and other comfort behaviour in a herring gull. Behaviour 63: 71-109.

3. Delius, J. D. 1970. The effect of daytime, tides and other factors on some activities of lesser black-backed gulls, Larus fuscus. Rev. Comp. Anim. 4: 3-11.

4. Traradri, V. 1966. Sleep in pigeon. Arch. Ital. Biol. 104: 516-521.

5. LEFEBVRE, L. 1982. The organization of grooming in budgerigars. Behav. Proc. 7: 93-106.

6. Delius, J. D. 1969. A stochastic analysis of the maintenance behaviour of skylarks. Behaviour 33: 137-178.

7. Slater, P. J. B. \& A. M. Wood. 1977. Does activation influence short-term changes in zebra finch behaviour? Anim. Behav. 25: 736-746.

8. VESTERGAARD, K. 1982. Dust-bathing in the domestic fowl-Diurnal rhythm and dust deprivation. Appl. Anim. Ethol. 8: 487-495.

9. Brown, N.S. 1974. The effect of louse infestation, wet feathers, and relative humidity on the grooming behavior of the domestic chicken. Poultry Sci. 53: 1717-1719.

10. Slater, P. J. B. 1974. Bouts and gaps in the behaviour of zebra finches, with special reference to preening. Rev. Comp. Anim. 8: 47-61.

11. LefebVRe, L. \& R. Joly. 1982. Organization rules and timing in kestrel grooming. Anim. Behav. 30: 1020-1028.

12. Fentress, J. C. 1972. Development and patterning of movement sequences in inbred mice. In The Biology of Behaviour. J. A. Krieger, Ed. Oregon Press. Eugene, Oregon.

13. NeCker, R. 1983. Somatosensory system. In Physiology and Behaviour of the Pigeon. M. Abs, Ed.: 171-219. Academic. London.

14. NECKER, R. 1985. Observations on the function of a slowly-adapting mechanoreceptor associated with filoplumes in the feathered skin of pigeons. J. Comp. Physiol. A 156: 391-394.

15. DeluUS, J. D. \& K. Bennetro. 1972. Cutaneous sensory projections to the avian forebrain. Brain. Res. 37: 205-221. 
16. Tinbergen, N. 1951. The Study of Instinct. Oxford Univ. Press. Oxford.

17. Hinde, R. A. 1970. Animal Behaviour: A Synthesis of Ethology and Comparative Psychology. 2 d edit. McGraw-Hill. New York.

18. VAN IERSEL, J. J. A. \& A. C. A. Bol. 1958. Preening in two tern species. A study of displacement activities. Behaviour 13: $1-88$.

19. Delrus, J. D. 1967. Displacement activities and arousal. Nature 214: 1259-1260.

20. Delus, J. D. 1970. Irrelevant behaviour, information processing and arousal homeostasis. Psychol. Forsch. 33: 165-188.

21. Rowel, C. H. F. 1961. Displacement grooming in the chaffinch. Anim. Behav. 9: 38-63.

22. Holland, H. C. 1976. Displacement activity as a form of abnormal behaviour in animals. In Obsessional States. H. R. Beech, Ed.: 161-173. Methuen. London.

23. LyON, D. O. \& L. TURNER, 1972. Adjunctive attack and displacement preening in the pigeon as a function of the ratio requirement for reinforcement. Psychol. Rec. 22: 509-514.

24. Fabricius, E. \& A. M. Jansson. 1963. Laboratory observations on the reproductive behaviour of the pigeon (Columba livia) during the pre-incubatory phase of the breeding cycle. Anim. Behav. 11: 534-547.

25. SpITERI, N. J. 1975. Social, especially agonistic behaviour in the pigeon. Masters thesis, Durham, England.

26. Bolton, T. B. 1976. Nervous system. In Avian Physiology. 2 d edit. P. D. Sturkie, Ed: 1-28. Springer. Berlin.

27. Gessa, G. L., M. Pisano, L. Vargiu, F. Crabal \& W. Ferrari. 1967. Stretching and yawning movements after intracerebral injection of ACTH. Rev. Can. Biol. 26: 229-236.

28. Delius, J. D., B. Craig \& C. Chaudorr. 1976. Adrenocorticotropic hormone, glucose and displacement activities in pigeons. Z. Tierpsychol. 40: 183-193.

29. Deviche, P.\& J. D. Delrus. 1981. Short-term modulation of domestic pigeon (Columba livia L.) behaviour induced by intraventricular administration of ACTH. Z. Tierpsychol. 55: 335-342.

30. Delus, J. D. 1985. The peck of the pigeon: Free for all. In Behaviour Analysis and Contemporary Psychology. C. F. Lowe, M. Richelle, D. E. Blackman \& C. M. Bradshaw, Eds.: 53-86. Lawrence Erlbaum Associates. Hillsdale, N. J.

31. GisPEN, W. H. \& R. L. ISAACSON. 1981. ACTH-induced excessive grooming in the rat. Pharmacol. Ther, 12: 209-246.

32. Neveling, U. 1981. Verhaltensänderungen bei Tauben induziert durch wiederholte intraventrikuläre Gaben von Adrenocorticotropem Hormon. Dipl. thesis, Bochum.

33. vON USLAR, A. 1983. Die Wirkung von Corticotropin und verwandten Peptiden auf das Verhalten der Taube. Dipl. thesis, Bochum.

34. Williams, N. S. \& D. L. SCAmpolr. 1984. Handling, ACTH, ACTH 1-24, and naloxone effects on preening behavior in domestic chickens. Pharmacol. Biochem. Behav. 20: $681-682$.

35. DUNCAN, I. J. H. \& D. G. M. WoOD-GUSH. 1972. An analysis of displacement preening in domestic fowl. Anim. Behav. 20: 68-71.

36. DunN, A. J., E. J. GREEN \& R. L. ISAACSON. 1979. Intracerebral adrenocorticotropic hormone mediates novelty-induced grooming in the rat. Science 203: $281-283$.

37. Brunelli, M., F. Magni, G. Morruzi \& D. Musumeci. 1975. Apomorphine pecking in the pigeon. Arch. Ital. Biol. 113: 303-325.

38. Deviche, P. 1985. Behavioral response to apomorphine and its interaction with opiates in domestic pigeon. Pharmacol. Biochem. Behav. 22: 209-214.

39. DevickE, P. 1983. Stereotyped behavior affected by peripheral and intracerebroventricular apomorphine administration in pigeons. Pharmacol. Biochem. Behav. 18: 323-326.

40. Lindenblatt, U. 1986. Die dopaminerge Auslösung des Pickverhaltens bei Tauben. Ph.D. thesis, Bochum.

41. Lindenblatt, U. \& J. D. Delius. 1986. Nucleus basalis prosencephali, a substrate for apomorphine elicited pecking in the pigeon. Submitted.

42. Dunn, A. J., J. E. Alpert \& S. D. Iversen. 1984. Dopamine denervation of frontal cortex or nucleus accumbens does not affect ACTH-induced grooming behaviour. Behav. Brain Res. 12: 307-315. 
43. Schall, U. \& J. D. Delius. 1986. Sensory inputs to the nucleus basalis prosencephali, a feeding-pecking centre in the pigeon. J. Comp. Physiol. A. 159: 33 41.

44. Schale, U., O. GÜnTürkǘn \& J. D. Delius. 1986. Sensory projections to the nucleus basalis prosencephali of the pigeon. Cell Tissue Res. 245: 539-546.

45. Schubert, B. 1982. Corticotropin induziertes Verhalten bei Tauben, Einfluss von Naloxon. Dipl. thesis, Bochum. 